\title{
LXV. On the length of the French mètre estimated in parts of the English Standard
}

\section{Captain Henry Kater F.R.S.}

To cite this article: Captain Henry Kater F.R.S. (1818) LXV. On the length of the French mètre estimated in parts of the English Standard, Philosophical Magazine Series 1, 52:248, 431-436, DOI: $10.1080 / 14786441808652075$

To link to this article: http://dx.doi.org/10.1080/14786441808652075

里 Published online: 23 Jul 2009.

Submit your article to this journal $\asymp$

Џll Article views: 3

Q View related articles $\square$

Citing articles: 1 View citing articles 5 
tion, and deduce from them the comparative lengths of the equivalent pendulum, $t, n^{\prime} t, n^{\prime \prime} t$, and $n^{\prime \prime \prime} t:$ and hence the value of $z$, of $v$, and of $t$ may be obtained, without determining $u$, and of course without employing the quantity $r$.

First, $\frac{z^{2}+v}{z+w}=t, \frac{z^{\prime 2}+v}{z^{\prime}+w}=n^{\prime} t, \frac{z^{\prime \prime}+v}{z^{\prime \prime}+w}=n^{\prime \prime} t, \frac{z^{\prime \prime \prime}+v}{z^{\prime \prime \prime}+w}=n^{\prime \prime \prime} t$.

II. $z+w=\frac{z^{2}+v}{t}, z^{\prime}+w=\frac{z^{\prime 2}+v}{n^{\prime} t}, z^{\prime \prime}+w=\frac{z^{\prime \prime}+v}{n^{\prime \prime} t}, z^{\prime \prime \prime}+w=\frac{z^{\prime \prime \prime}+v}{n^{\prime \prime \prime} t}$. III. $z-z^{\prime}=d^{\prime} ; z-z^{\prime \prime}=d^{\prime \prime} ; z-z^{\prime \prime \prime}=d^{\prime \prime \prime}$.

IV. $d^{\prime}=\frac{z^{2}+v}{t}-\frac{z^{\prime 2}+v}{n^{\prime} t} ; d^{\prime \prime}=\frac{z^{a}+v}{t \cdot}-\frac{z^{\prime \prime \prime}+v}{n^{\prime \prime} t} ; d^{\prime \prime \prime}=\frac{z^{2}+v}{t}-\frac{z^{\prime \prime \prime}+v}{t^{\prime \prime \prime} t}$. V. $t=\frac{z^{2}+v}{d^{t}}-\frac{z^{\prime 2}+v}{n^{\prime} d^{\prime}}=\frac{z^{2}+v}{d^{\prime \prime}}-\frac{z^{\prime \prime 2}+v}{n^{\prime \prime} d^{\prime \prime}}=\frac{z^{2}+v}{d^{\prime \prime \prime}}=\frac{z^{\prime \prime \prime}+v}{n^{\prime \prime \prime} d^{\prime \prime \prime}}$.

VI. By comparing the first of these equations successively with the second and third, and bringing the terms containing $v$ to the same side, we obtain

$$
\begin{aligned}
v= & \left(\frac{z^{2}}{d^{\prime}}-\frac{z^{\prime 2}}{n^{\prime} d}-\frac{z}{a^{\prime \prime}}+\frac{z^{\prime \prime 2}}{n^{\prime \prime} d^{\prime \prime}}\right):\left(\frac{1}{a^{\prime \prime}}-\frac{1}{n^{\prime \prime} d^{\prime \prime}}-\frac{1}{d^{\prime}}+\frac{1}{n^{\prime} d^{\prime \prime}}\right)= \\
& \left(\frac{z^{2}}{d^{\prime \prime}}-\frac{z^{\prime 2}}{n^{\prime} d}-\frac{z^{2}}{d^{\prime \prime \prime}}+\frac{z^{\prime \prime \prime}}{n^{\prime \prime \prime} d^{\prime \prime \prime}}\right):\left(\frac{1}{a^{\prime \prime \prime}}-\frac{1}{n^{\prime \prime \prime} d^{\prime \prime \prime}}-\frac{1}{d^{\prime}}+\frac{1}{n^{\prime} d^{\prime}}\right) .
\end{aligned}
$$

"This equation contains only the squares of the values of $z$ with known coefficients; and if we substitute $z-d^{\prime}, z-d^{\prime \prime}$, and $z-d^{\prime \prime \prime}$ for $z^{\prime}, z^{\prime \prime}$, and $z^{\prime \prime \prime}$, respectively, we shall obtain an equation in the form $e z^{2}+f z=g$, whence $z= \pm \sqrt{ }\left(g+\frac{1}{4} f^{2}\right)-\frac{1}{2} f$.

LXV. On the Length of the French Metre estimated in Parts of the English Standard. By Captain Henry Kater, H.R.S.**

0 NE of the objects of the Committee of the Royal Society appointed for the purpose of determining the length of the seconds pendulum, being the comparison of the French mètre with the British Standard Measure, two mètres were procured from Paris for that purpose, the one made in the usual manner, and called the mètre à bouts, and the other a bar of platina, on which the length of the metre is shown by two very fine lines; this is named the mètre à traits.

The width of the mètre à bouts is one inch, and its thickness 0.3 of an inch. On one side the word "METRE" is engraved,

* From the Transactions of the Royal Society for 1818, Part I. 
and on the other "Fontro à Paris." The terminating planes are supposed to be perfectly parallel, and the distance between them is the length of the mistre.

The mètre à traits is the same width as the mètre à bouts, but only a quarter of an inch thick. The lines expressing the length of the mètre are so fine that one of them is scarcely perceptible even with the assistance of a microscope, unless the light be very favourable. The situation of the lines may however be discovered by two strong black dots, made with a graver at the extremities of each, and a fine line crosses them at right angles, to indicate the parts from which the measurements are to be taken.

This mètre, previous to being brought from Paris, was compared with a standard mètre by M. Arago, with all that care and ability which he is so well known to possess, and which so delicate an operation reyuires. The result was, that the distance between the lines was found to be less than a mètre by $\frac{17.59}{1000}$ of a millimètre, or $\cdot 00069$ of an inch.

The same micrometer microscopes were used in the comparisons which I am about to detail, as have been already described in my account of experiments on the length of the pendulum in the Philosophical Transactions of the present year: and as the length of the uretre is nearly 39.4 inches, I was enabled to refer it to the same divisions of Sir George Shuckburgh's scale as I had employed in the measurement of the pendulum.

I commenced with the mètre à iraits. It was placed in contact with the standard scale, their surfaces being in the same plane. An excellent thermometer was laid upon the scale, and a piece of thick leather was placed upon its bulb in order to prevent its being affected by heat from the person of the observer.

The whole was suffered to remain in this state for two or three days; after which the following observations were made at various times, the microscopes being brought alternately over the mètre and the scale. The value of each division of the micrometer is $\frac{1}{2} \frac{1}{30}$ of an inch*.

* For the manner in which this value was obtained, see page 175 of the preceding paper. 
estimated in Parts of the English Standard.

Comparison of the Meire à traits.

\begin{tabular}{|c|c|c|c|c|c|c|}
\hline 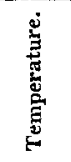 & 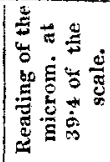 & 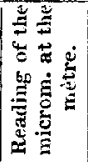 & 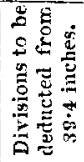 & 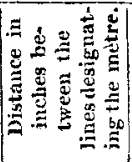 & 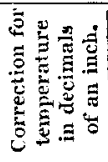 & $\begin{array}{l}\text { Distauce in inches } \\
\text { between the lines } \\
\text { designating the } \\
\text { metre, the metre } \\
\text { being at } 390 \text {, and } \\
\text { the scale at } 62^{\circ} \text {. }\end{array}$ \\
\hline $60 \cdot 0$ & 850 & $644 \cdot 5$ & $559 \cdot 5$ & $39-37606$ & .100604 & 3937012 \\
\hline $60 \cdot 7$ & $75 \cdot 5$ & 139.0 & 563.5 & $39 \cdot 37588$ & $\cdot 100599$ & 39.36999 \\
\hline $61 \cdot 7$ & $69 \cdot 2$ & $634 \cdot 0$ & $564 \cdot 8$ & 59.37583 & $\cdot 00568$ & $39 \cdot 37015$ \\
\hline $62 \cdot 0$ & 650 & $630 \cdot 5$ & $56 j 5$ & $39 \cdot 37580$ & .00562 & 39.57018 \\
\hline $62 \cdot 4$ & 61.0 & 629.0 & 568.0 & 39.37569 & .00554 & 39.37015 \\
\hline $62 \cdot 3$ & 58.7 & $629 \cdot 5$ & $570 \cdot \mathrm{y}$ & $39 \cdot 37557$ & .00556 & $39 \cdot 37001$ \\
\hline $62 \cdot 2$ & $58 \cdot 0$ & 6230 & 5700 & $39 \cdot 37560$ & .00558 & 59.57002 \\
\hline $62 \cdot 2$ & 59.0 & 6250 & $566 \cdot 0$ & 39.37577 & -1)0558 & 39.57019 \\
\hline 62.1 & $59 \cdot 0$ & 625.5 & 5665 & 5937575 & $\cdot 00560$ & $39 \cdot 37015$ \\
\hline 58.8 & 900 & $638 \cdot 0$ & $548 \cdot 0$ & $39 \cdot 37654$ & .00629 & 9.37025 \\
\hline 50.0 & 83.0 & $637 \cdot 0$ & $554 \cdot 0$ & $59 \cdot 37629$ & .013625 & $29 \cdot 37104$ \\
\hline $59 \cdot 0$ & $82 \cdot 0$ & 6360 & $5.54 \cdot 1)$ & $39 \cdot 37629$ & .00625 & $59 \cdot 37004$ \\
\hline $59 \cdot 2$ & $83 \cdot 2$ & $632 \cdot 0$ & 5488 & $39 \cdot 37651$ & .00621 & $39.5 \% 030$ \\
\hline $59 \cdot 1$ & 81.0 & 632.0 & $5 j 1 \cdot 0$ & $39 \cdot 37642$ & .00623 & 3937019 \\
\hline \multirow{4}{*}{\multicolumn{6}{|c|}{ 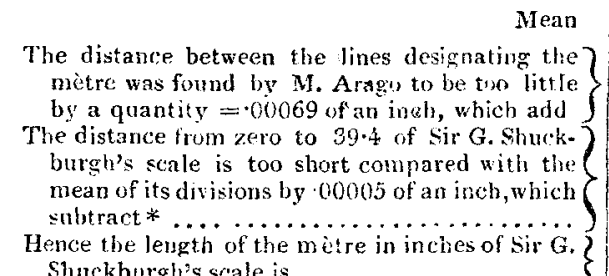 }} & 39.57012 \\
\hline & & & & & & $\div 000 \cdot 69$ \\
\hline & & & & & & -00005 \\
\hline & & & & & & 39.37076 \\
\hline
\end{tabular}

The comparison of the metre à bouts presented considerable difficulties, which I conceive it would be of little use to detail, as the necessity of comparisons of this kind is of very rare occurrence; I shall therefore proceed to describe the method which was at last found successful.

Four rectangular pieces of brass were prepared precisely similar to those described in the account of experiments on the pendulum in the Philosophical Transactions hefore referred to. These were marked $\mathrm{C}, c, \mathrm{D}$ and $d$. The perfectly plane rectangular edges of the pieces $\mathrm{C}$ and $c$, being placed in contact, and kept thus by means of a spring, the distance of the fine lines drawn on their surfaces, parallel and very near to the rectangular edges, was found to be 500.5 divisions of the micrometer; and the pieces $\mathrm{D}$ and $d$ being placed in like manner in contact, the distance of the lines on their surfaces estimated in the same divisions was $456 \cdot 7$.

The mètre à louts being placed by the side of the brass scale and in contact with it, the pieces $\mathrm{D}$ and $d$ were applied to its extremities, the surfaces of the brass pieces being a little below the surface of the mètre in order to preclude any error which * See page 176.

Vol. 52. No. 248. Dec. 1818.

E e

might 
might have arisen from the edges of the mètre projecting beyond its terminating planes. Each of the brass pieces was supported in this position upon a picce of lead of a sufficient thickness, and kept in close contact with the end of the mètre by means of a slight spring bearing against a pin driven perpendicularly into the lead.

In order to ensure a perfect contact between each brass piece and the terminating plane of the mètre, a fat ruler of brass was laid upon the surface of the metre so as to project beyond its extremity, and the end of the lead was elevated or depressed so that the line of light seen between the piece of brass and the ruler, the eye being level with the surface of the brass, apppeared to be equal in every part; when it was inferred that the surfaces of the metre and of the piece of brass were parallel, and consequently that their rectangular ends were perfectly in contact.

The distance hetween the lines on $\mathrm{D}$ and $d$ was now taken by the microscopes, and transferred to the scale in the manner before described; and when a sufficient number of comparisons had thus been made, the pieces $\mathrm{D}$ and $d$ were exchanged for those marked $\mathrm{C}$ and $c$, and the observations repeated with every precaution to ensure an accurate result, especially with respect to temperature.

The under surface of the mètre was then placed uppermost, and the apparatus being arranged as before, the same process was pursued as that which has just been described. The results are contained in the following tables.

Comparison of the Metre à bouts.

\begin{tabular}{|c|c|c|c|c|c|c|c|}
\hline \multicolumn{8}{|c|}{$\begin{array}{c}\text { The pieces } \mathrm{D} \text { and } d \text { applied. Distance from } \mathrm{D} \text { to } d \text {, } \\
456.7 \text { divisions. The word Metre above. }\end{array}$} \\
\hline 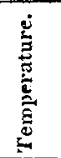 & 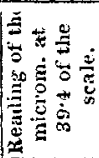 & 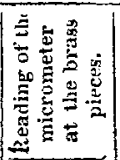 & 㟒 & 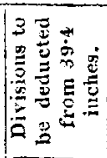 & 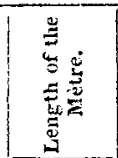 & 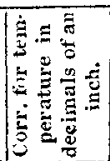 & 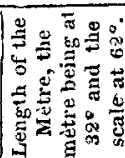 \\
\hline $59 \cdot 7$ & 95 & 915 & 890 & $538 \cdot 7$ & $39 \cdot 37692$ & .00610 & 13937083 \\
\hline $4 \cdot 8$ & 38 & & & & & & 079 \\
\hline 50 & 39 & & 59 & $515 \cdot 7$ & & 00709 & 084 \\
\hline $5 \cdot 1$ & $36^{\circ} ?$ & & 58 & $5 \mathrm{lj} \cdot 5$ & $: 59 \cdot 3$ & $\mid 00707$ & $39 \cdot 37087$ \\
\hline $55 \%$ & 360 & $9.5 \%$ & $59 \cdot 0$ & $51.5 \cdot 7$ & & 00705 & $39 \cdot 37088$ \\
\hline \multicolumn{8}{|c|}{ viean | :54.37084 } \\
\hline \multicolumn{8}{|c|}{$\begin{array}{c}\text { The pieces } \mathrm{C} \text { and } c \text { applied. Distance from } \mathrm{C} \text { to } c \text {, } \\
500.5 \text { divisions. The word Metre ahove. }\end{array}$} \\
\hline $5 \cdot 6$ & $3: 1 \cdot 7$ & 47 & 10 & . & 1613070 & & $5 y, 01090$ \\
\hline 55.7 & 00 & & & & & & \\
\hline & $30 \cdot 2$ & 47 & 17 & & $39 \cdot 37$ & & $39 \cdot 57094$ \\
\hline $6 \cdot 2$ & 24.5 & & & & $39 \cdot 37$ & & $59 \cdot 37086$ \\
\hline 6 & 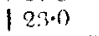 & 44 & $21{ }^{\circ}-2-$ & 52 & 39377 & 00681 & 39.37084 \\
\hline \multicolumn{8}{|c|}{ Мलя⿻ } \\
\hline
\end{tabular}




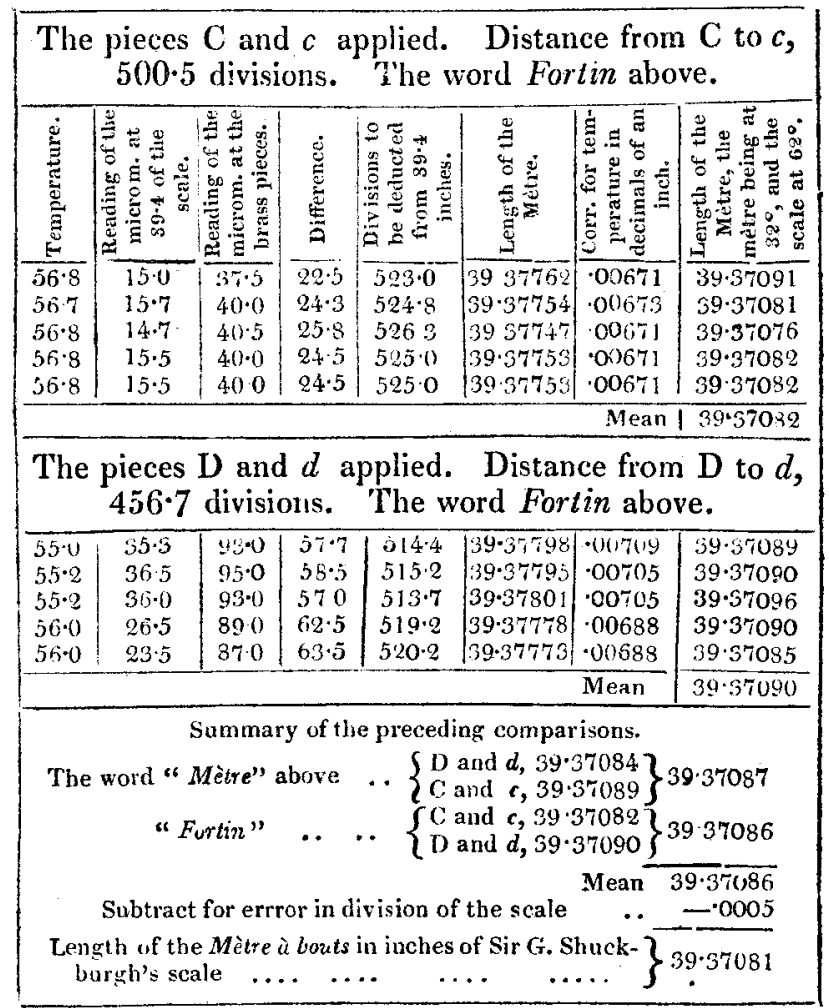

The following is the manner in which the correction for temperature was obtained. The expansion of platina according to the experiments of Borda and others, is $\cdot 00000476$ parts of its length for one degree of Fahrenbeit; and as this is the expansion used by the French in adjusting the length of their metre, it must be employed on the present occasion. The mètre being taken at $32^{\prime \prime}$, the expansion for the difference between this and the temperature of measurement must be subtracted from the apparent length of the metre. The English standard temperature is $62^{\circ}$ : therefore, if the temperature of measurement be under this, the expansion of the scale for such difference of temperature must be deducted from the length of the mètre before obtained. These two corrections are combined in the column entitled "Correction for temperature." Sir G. Shuckburgh's standard scale is of cast brass; and as I could not conveniently determine its actual expansion with that degree of accuracy that would have satisfied me, I have taken for it, the mean result of two exE e 2 periments 


\section{On the Preservation of Seeds, the Use of Lime in}

periments made on plate brass, which gave me an expansion of -0000101 parts of its length for one degree of Fahrenheit. The mean of most of the experiments made on the expansion of brass gives $\cdot 0000104$, and had I employed this last number instead of my own, the difference in the length of the mètre would have been utterly inconsiderable.

Supposing then both mètres to be of equal authority, we have for the length of the metre a traits $39 \cdot 57076$, and for that of the mètre à louts 39.37081 inches; the mean of which, 39.37079, may be taken for the length of the mètre in inches of Sir G. Shuckburgh's standard scale when each is brought to its proper temperature *.

London, Norember 1817.

* The length of the mètre compared with Bird's Parliamentary standard is $39 \cdot 37062$ inches.

LXVI. On the Preservation of Seeds, the Use of Lime in Agri. culture, and former State of Cultivation in Scolland. By Mr. Gavin Inglis.

\section{To Mr. Tilloch.}

SIR, - I Do not know what philosophical attention may have been bestowed on the self-preservation of seeds, or the apparent spontaneous evolution of indigenous plants. The subject is certainly interesting, and may well claim the attentive regard of those whose leisure and abilities may be fit for this branch of instructive knowledge. From the little experience and scanty opportunity of observation that have fallen to my lot, I can do nothing towards the elucidation of so important a research ; but from the memorandums of what has come within my practice, $I$ shall select a few occurrences that struck me as deserving of notice, and which, although not conclusive in themselves, may still be of some use to others better qualified for the task. From what I have observed, I am very much inclined to think that seeds, particularly those of the oily kinds, when mixed with cold earth, and lying at a depth in dry soil beyond the congenial influence of the sun's vivific rays, will never lose their vital atom, or vegetative principle, but will remain for ever dormant, unless by design or accident the substratum be raised, and the seed-bed brought within the reach of the sun's influence. These seeds must owe their incorruptibility to some self-preserving principle, and their dormancy to the debarred approach of the solar streams of light. Without admitting some such ratiocination, how is it possible to reconcile or account for the spontaneous production of the great variety of plants and flowers, apparently 